\title{
Editorial
}

\section{La implementación de los Acuerdos de Paz y el desarrollo en Colombia}

http://doi.org/10.14718/revfinanzpolitecon.2019.11.2 .1

\author{
Joan Miguel Tejedor-Estupiñan*
}

Colombia es un país multicultural y pluriétnico, rodeado por dos océanos, miles de páramos, lagunas y ríos que nacen en la compleja geografía creada por tres sistemas de cordilleras. Un territorio que desde sus puntos más altos y hasta las llanuras y selvas —como el Tapón del Darién o el Amazonas - hace posible una variedad casi infinita de ecosistemas y formas de vida que han posicionado al país dentro del exclusivo grupo de naciones megadiversas del mundo. Una nación rica en energía solar, eólica, fluvial, recursos minerales, agrícolas y marítimos, pero con sectores industriales y de servicios aún en fase de desarrollo. Un país donde los altos niveles de violencia, pobreza y desigualdad aún son parte de su realidad.

Un hecho histórico que viene transformando la sociedad colombiana sucedió el 24 de noviembre del 2016, cuando se firmó el Acuerdo Final para la Terminación del Conflicto y la Construcción de una Paz Estable y Duradera entre el Gobierno de Colombia y las Fuerzas Armadas Revolucionarias de Colombia (FARC-EP), cuyo propósito era cerrar un capítulo del conflicto armado interno que durante más de seis décadas generó violencia e inestabilidad a lo largo y ancho del territorio nacional (Gobierno de Colombia y FARC-EP, 2016). El Acuerdo Final pretendía contribuir al mejoramiento de una compleja realidad: un conflicto armado originado por otros actores como el Ejército de Liberación Nacional (ELN), el Ejército Popular de Liberación (EPL), los narcotraficantes, los paramilitares, las bandas criminales emergentes e incluso bandas delincuenciales y corruptas que actúan organizadas dentro de las diferentes instituciones y corporaciones que componen los poderes Ejecutivo, Legislativo y Judicial del Estado colombiano (Centro de Memoria Histórica, 2013).

Unido a los fenómenos del conflicto y la violencia, el desarrollo ambiental, social y económico en Colombia se ve amenazado por altos niveles de deforestación, explotación de recursos minerales y combustibles fósiles en territorios de alto valor ecológico y ambiental, contaminación del aire, los ríos y la tierra cultivable. Además, el desarrollo humano y económico está siendo afectado negativamente por altos niveles de desigualdad, pobreza, desempleo, informalidad, así como por

Ph.D. (C) en Economía, magíster en Derechos Humanos y economista. Editor de la revista Finanzas y Política Económica, de la Universidad Católica de Colombia. Correo electrónico: jmtejedor@ucatólica.edu.co. Dirección de correspondencia: Facultad de Economía, Universidad Católica de Colombia, Carrera 13 n. ${ }^{\circ}$ 47-49 (Bogotá, Colombia). (D) Orcid: https://orcid.org/0000-0002-2346-3222 
bajos niveles de productividad y desindustrialización. A pesar de que Colombia haya sido admitida dentro de la Organización para la Cooperación y el Desarrollo Económicos (OCDE), los indicadores manifiestan una evidente violación a los derechos económicos, culturales, sociales y ambientales de los colombianos.

Según el informe Latinobarómetro 2018, solamente el 13\% de los ciudadanos latinoamericanos estaban de acuerdo con las políticas de sus gobiernos, una gran reducción en comparación con el 30\% registrado en el 2017. En el 2018, en Colombia solo el 16\% de los encuestados expresaron tener confianza en los partidos políticos, $20 \%$ afirmaron que confiaban en el Congreso y $22 \%$ manifestaron confiar en el Gobierno. Para los colombianos, el principal problema por superar es la corrupción (Corporación Latinobarómetro, 2018). El informe de Transparencia Internacional (2017), que presenta el índice de percepción de la corrupción, señala que en Colombia la tasa de soborno es del 37\%, la más alta de la región. El Informe de perspectivas económicas para América Latina de la OCDE (2018) también subrayaba que el 79\% de los latinoamericanos creen que sus gobiernos son corruptos, doce puntos más que lo registrado en el 2010. Según el informe, Colombia se encuentra en los últimos lugares del ranking (OCDE, CAF y ECLAC, 2018).

El Informe global de capital humano (Foro Económico Global, 2017) localiza a Colombia en el puesto 68 sobre la media de la región y subraya que los niveles de desempleo han superado el 6,7\% y siguen aumentando. Igualmente, el Índice de Democracia 2017 categoriza a Colombia como una democracia débil (The Economist Intelligence Unit, 2018); en una escala de 0 a 10, donde 10 es el más alto, Colombia obtuvo en el 2017 un puntaje de 6,67. Estos indicadores muestran al Gobierno entrante los principales retos de gobernanza y gobernabilidad a los que debe hacer frente, incluyendo la implementación del Acuerdo Final de Paz con las FARC y la continuación de las conversaciones con otros grupos al margen de la ley.

La corrupción y el conflicto armado en Colombia son los principales obstáculos tanto para el desarrollo humano y económico como para el respeto de los derechos humanos y los derechos económicos, sociales, culturales y ambientales; por ello, conviene resaltar tres momentos electorales que en los últimos cuatro años marcaron los procesos contemporáneos de transformación política, social y económica que hoy atraviesa el país:

a. El Plebiscito por la Paz del 2 de octubre del 2016, donde la pregunta formulada a los colombianos fue: “¿Apoya usted el Acuerdo final para la terminación del conflicto y la construcción de una paz estable y duradera?". Los resultados mostraron que, de casi 34,9 millones de personas habilitadas para votar, solo el 37,46\% participaron de esta contienda electoral, donde el 49,78\% de los electores votaron SÍ y un 50,21\% votaron NO (Registraduría Nacional del Estado Civíl, 2016). El Acuerdo Final fue ratificado por el Congreso de la República de Colombia.

b. La Consulta Anticorrupción del 26 de agosto del 2018, donde el mecanismo de participación alcanzó el 32,05\% del censo electoral y no superó el umbral de participación 
exigido por el literal $c$ del artículo 41 de la Ley 1757 de 2015, por lo cual se estancaron en la agenda de política pública temas como reducir el salario de los congresistas y altos funcionarios del Estado, cárcel a corruptos y prohibirles volver a contratar con el Estado, contratación transparente obligatoria en todo el país, presupuestos públicos con participación de la ciudadanía, rendición de cuentas de asistencia, votación y gestión de los congresistas, hacer públicas las propiedades e ingresos injustificados de políticos elegidos, extinguiéndoles el dominio, y un máximo de tres periodos en corporaciones públicas (Registraduría Nacional del Estado Civíl, 2018a).

c. Las elecciones presidenciales del 17 de junio del 2018 en Colombia, en cuya segunda vuelta el candidato del partido Centro Democrático (partido liderado por Álvaro Uribe Vélez) Iván Duque Márquez venció con 10.373 .080 votos (53,98\%) a Gustavo Petro, del movimiento Colombia Humana, que contó con 8.034.189 votos (41,81\%) (Registraduría Nacional del Estado Civíl, 2018b).

Mientras el primer proceso se presentaba como una solución parcial del conflicto armado con Colombia, el segundo constituía una esperanza para disminuir los niveles de corrupción que frenan el desarrollo. Con la elección de Iván Duque se marca un cambio de sentido en la política nacional, tras su propuesta de cambiar el Acuerdo de Paz, al considerarlo demasiado indulgente con los exguerrilleros de las FARC, y con la promesa de gobernar para las clases populares, reduciendo los impuestos y aumentando los salarios. A un año de gobierno, los resultados frente a los retos sociales y económicos son desalentadores; las críticas se relacionan con aspectos como la injerencia en los asuntos de Venezuela y la falta de atención a la crisis humanitaria que se vive a nivel nacional, donde desde la firma del Acuerdo 137 excombatientes de las FARC han sido asesinados (Revista Semana, 2019). Y mientras el Gobierno anunciaba dentro de sus logros la erradicación de 80.000 hectáreas de coca, o de haber creado 60.000 empleos en un año (habiendo prometido crear 600.000 en cuatro años), la ONU ubica a Colombia como el productor del $80 \%$ de la cocaína que se exporta hacia el mundo (UNODC, 2019).

Las dinámicas no han mejorado en un año ni para este gobierno ni para el país, y la falta de gobernanza se ha evidenciado tanto en la caída de la Ley de Financiamiento y la propuesta de reforma a la justicia como en la objeción de la Jurisdicción Especial para la Paz (JEP), que finalmente tuvo que firmarse (The Economist, 2019). La devaluación del peso colombiano con respecto al dólar $\mathrm{y}$ al euro es uno de los principales indicadores de la falta de productividad por la que atraviesa la economía colombiana. El desempleo pasó del 9,2\% en agosto del 2018 al 10,8\% en agosto del 2019 (DANE, 2019). Finalmente, se prevé que el crecimiento económico para el 2019 sea menor al 3,0\% (Portafolio, 2019).

La realidad que se vislumbra en las cifras presentadas deja ver que los principales temas de la agenda nacional son la superación del conflicto armado y la reducción de la brecha del desarrollo humano, social y económico. Ciertamente se espera que el gobierno garantice la implementación 
del Acuerdo Final firmado con las FARC y que se cumplan las promesas de campaña, entre otras, las de generar emprendimiento con la economía naranja y gravar impositivamente a los más ricos para mejorar las condiciones de la clase trabajadora. De no ser así, es posible que surja un descontento de diferentes sectores de la sociedad civil, que se manifestarán por sus derechos y frente al incumplimiento de las metas del Gobierno, por lo cual deberá generarse un diálogo nacional para la salida negociada a las problemáticas citadas.

Con el ánimo de aportar desde los escenarios científicos, la revista Finanzas y Política Económica presenta en su nueva edición un grupo de nueve documentos originados en países como México, España, Jordania y Colombia, los cuales abordan temas como el Teorema de Rolle y su relación con las tasas internas múltiples de retorno, los determinantes del balance comercial bilateral de México, el desarrollo del desarrollo de la infraestructura de transporte y la competitividad en los países miembros de la Alianza del Pacífico, los efectos de las tarjetas de crédito en la estructura de consumo y la desigualdad de los hogares mexicanos, la gestión de residuos sólidos urbanos en América Latina, los escenarios de un turbulento Brexit, la integración entre mercados de petróleo de diferente calidad basado en las correlaciones condicionales dinámicas, la estructura de capitalnexo de valor de la empresa como papel moderador de la rentabilidad y, finalmente, el efecto de la heurística de anclaje y ajuste y el sesgo de optimismo en los pronósticos del mercado de valores.

\section{REFERENCIAS}

1. Centro de Memoria Histórica. (2013). iBasta Ya! Colombia: Memoria de guerra y dignidad. Bogotá: Autor. http://www.centrodememoriahistorica.gov.co/descargas/informes2013/bastaYa/basta-ya-colombia-memo rias-de-guerra-y-dignidad-2016.pdf

2. Corporación Latinobarómetro (2018). Latinobarómetro Report 2018. Santiago: Autor. http://www.latinobarometro.org/lat.jsp

3. Departamento Administrativo Nacional de Estadística (DANE) (2019). Gran Encuesta Integrada de Hogares (GEIH) - Mercado laboral. https://www.dane.gov.co/index.php/estadisticas-por-tema/ mercado-laboral/empleo-y-desempleo

4. Gobierno de Colombia y FARC-EP (2016). Acuerdo Final para la Terminación del Conflicto y la Construcción de una Paz Estable y Duradera. La Habana. https://www.mesadeconversaciones.com.co/sites/default/files/2 4_08_2016acuerdofinalfinalfinal-1472094587.pdf

5. OECD/CAF/ECLAC (2018). Latin American Economic Outlook 2017: Rethinking Institutions for Development. París: Autor. https://doi.org/10.1787/leo-2017-en

6. Portafolio (2019). Economía colombiana crecería por debajo del 3\% en el 2019. https://www.portafolio. co/economia/proyecciones-crecimiento-colombia-531855

7. Registraduría Nacional del Estado Civil (2016). Resultados Plebiscito 2 octubre 2016 - República de Colombia. https://elecciones.registraduria.gov.co/pre_plebis_2016/99PL/DPLZZZZZZZZZZZZZZZZZ_L1.htm 
8. Registraduría Nacional del Estado Civil (2018a). Consulta Anticorrupcion 2018. https://www.registraduria. gov.co/-Consulta-Anticorrupcion-2018-.html

9. Registraduía Nacional del Estado Civil (2018b). Registraduría Nacional del Estado Civil - Revocatoria del mandato. https://www.registraduria.gov.co/-Presidencia-.html

10. Revista Semana (2019). Radiografía de los asesinatos contra exguerrilleros de las Farc. https://especiales. semana.com/crimenes-en-contra-de-las-farc/137-asesinatos-y-contando.html

11. The Economist (2019). Can Colombia's President Iván Duque find his feet? http://www.economist.com/ the-americas/2019/06/20/can-colombias-president-ivan-duque-find-his-feet

12. The Economist Intelligence Unit (2018). Democracy Index 2017. The Economist- The Intelligent Unit. London. https://www.eiu.com/topic/democracy-index

13. Transparencia International (2017). Corruption Perceptions Index 2017. https://doi.org/978-3-943497-18-2

14. UNODC (2019). World Drug Report 2019. http://wdr.unodc.org/wdr2019/

15. Foro Económico Mundial (2017). The Global Human Capital Report 2017. https://doi.org/ISBN 978-1-944835-10-1 